\title{
Mulemba
}

Revista Angolana de Ciências Sociais

6 (11) | 2016

Políticas, direitos e práticas da sociedade e do Estado

\section{Tendências internacionais na gestão e administração da educação: políticas de descentralização e autonomia}

International trends in the management and administration of education:

policies of decentralization and autonomy

Pedro Manuel Patacho

(2) OpenEdition

Journals

Edição electrónica

URL: http://journals.openedition.org/mulemba/1355

DOI: 10.4000/mulemba.1355

ISSN: 2520-0305

Editora

Edições Pedago

Edição impressa

Data de publição: 1 maio 2016

Paginação: 85-100

ISSN: 2182-6471

Refêrencia eletrónica

Pedro Manuel Patacho, «Tendências internacionais na gestão e administração da educação: políticas de descentralização e autonomia», Mulemba [Online], 6 (11) | 2016, posto online no dia 01 outubro

2018, consultado o 26 janeiro 2021. URL: http://journals.openedition.org/mulemba/1355 ; DOI: https:// doi.org/10.4000/mulemba.1355 


\title{
Tendências internacionais na gestão e administração da educação: políticas de descentralização e autonomia
}

\author{
Pedro Patacho*
}

\begin{abstract}
Resumo: A autonomia das escolas, enquanto política de gestão e administração pública, resulta de um processo gradual de transferência de poderes de decisão para as instituições educativas, acompanhado da definição de mecanismos de prestação de contas perante a tutela. No seu início, as reformas em matéria de autonomia das escolas estiveram sobretudo relacionadas com a causa política da participação democrática e com a ideia de justiça social, realçando a necessidade de as escolas se abrirem às respectivas comunidades locais. Esta preocupação foi perdendo força nas últimas décadas, à medida que uma outra se lhe sobrepôs, sobretudo influenciada pela agenda de uma nova gestão pública que, servida por uma ideologia neoliberal, pretende aplicar os princípios do sector privado à gestão dos serviços públicos. No caso do sector da educação, o efeito mais visível tem sido uma acentuada mercantilização - e consequente reconceptualização - da escola pública por via destas políticas de descentralização e autonomia. Pelo caminho, foram caindo no esquecimento as verdadeiras razões pelas quais se formaram os sistemas educativos públicos e foi-se perdendo gradualmente a ideia de que o principal objectivo que deveria guiar as reformas e as inovações educativas deveria ser o de garantir uma maior justiça social e uma melhor democracia.
\end{abstract}

Palavras-Chave: Autonomia, descentralização, políticas públicas, gestão e administração escolar.

\section{Intróito}

Numa esplêndida comunicação aquando da Trienal das Humanidades - I Congresso 2014, que decorreu em Luanda entre 11 e 18

* Professor adjunto e investigador do Centro de Investigação do Instituto Superior de Ciências Educativas (CI-ISCE), Lisboa, Portugal; Professor convidado e investigador coordenador do Centro de Recursos Pedagógicos (CEREPE) da Faculdade de Ciências Sociais (FCS) da Universidade Agostinho Neto (UAN), Luanda, Angola. 
de Abril, o Professor Arlindo Barbeitos citava Immanuel Wallerstein para afirmar que as palavras estão poluídas. E se há campo em que esta é uma verdade irrefutável é o campo das políticas públicas, sobretudo na provisão de serviços essenciais como é o caso da educação. De facto, vários termos e expressões cujo significado era até há poucas décadas tido como inquestionável, sofreram entretanto importantes processos de (re)significação e estruturam hoje um novo senso-comum que, circulando de forma sedutora (KuMASHIRO 2008) pelos fluxos comunicacionais desta era da informação, é aceite com toda a naturalidade pela opinião pública (BAUMAN 2011). Usam-se as mesmas palavras, mas em muitos casos elas já não significam as mesmas coisas.

Esta é uma evidência particularmente marcante das economias desenvolvidas que tantas vezes são tidas como casos de estudo para a análise e adaptação de modelos de gestão pública por parte dos países em desenvolvimento. Convém, portanto, que não percamos de vista a necessidade de escavar no passado para compreendermos melhor ideias e conceitos que hoje surgem com uma determinada roupagem, que à primeira vista nos pode parecer tão natural quanto evidente, mas que entretanto abandonou boa parte do seu sentido original.

No que diz respeito ao sector da educação, é importante perceber que os sistemas educativos contemporâneos são o resultado de uma construção social e histórica no seio de determinadas dinâmicas de poder às quais não são alheias questões ideológicas. Em cada período sócio-histórico, as tensões sociais e políticas em presença resolvem-se no sentido de conformar sistemas educativos com um determinado perfil, mas que poderia eventualmente ser outro, assim se resolvessem de outra forma essas mesmas tensões (VIÑAO 2007).

Deste ponto de vista, as grandes tendências internacionais que nas últimas décadas têm influenciado as reformas educativas na maior parte dos países desenvolvidos não podem deixar de ser associadas à consolidação do capitalismo enquanto modelo de desenvolvimento dominante (CASTELLS 2007), servido por uma ideologia neoliberal que tem conseguido influenciar a resolução daquelas tensões num determinado sentido, desembocando-se assim no desenho de políticas públicas que em boa parte resultam dessa influência ideológica.

$\mathrm{O}$ que tem vindo a acontecer de forma gradual, como tem defendido Boaventura de Sousa Santos (2006), é um cada vez mais visível desequilíbrio da tensão permanente entre aqueles que historicamente têm sido os três grandes pilares reguladores da vida social: o Estado, 
o mercado e a cidadania. Desde há algumas décadas a esta parte que o mercado vem capturando o Estado, com o consentimento acrítico da população e das diversas classes profissionais do sector público, muitas vezes mais preocupadas com os seus interesses corporativos de classe do que com o serviço da causa pública e a construção do bem-comum.

O argumento central deste texto é o de que as políticas públicas de descentralização e autonomia, em particular na gestão e administração das instituições escolares, inicialmente relacionadas com a causa política da participação democrática dos cidadãos e com a ideia de justiça social, foram gradualmente capturadas pela ideologia neoliberal, provocando uma reconceptualização da provisão de serviços públicos de educação, hoje claramente alinhados com uma perspectiva managerialista (GERWITZ 2002) cujo resultado, a prazo, tende para a mercantilização da educação pública (РАтAcho 2013).

\section{Educação escolar e neoliberalismo}

A crescente influência que os modelos de gestão empresarial foram tendo sobre os sistemas educativos (Torres SANTOMÉ 1998; 2000; 2001) visou sobretudo reorientar as finalidades da escolarização de acordo com as necessidades económicas de produção do capitalismo global. Essa reorientação foi sendo apresentada como necessária e indispensável, oculta em expressões eufemísticas como «reformas estruturais» e apoiada em discursos demagógicos que «insistem continuamente no estabelecimento de relações directas entre os sistemas educativos e a produtividade dos mercados» (ToRrES SANTOMÉ 2001: 29).

No fundo, aquilo a que se foi assistindo foi a uma espécie de universalização da ética empresarial que passou a dominar a maior parte dos aspectos da vida quotidiana dos cidadãos. Uma nova forma de liberalismo que se consolida «no contexto das estratégias de transformação da globalização do capital [...] e da retirada e do descomprometimento [do] Estado de uma ampla gama de assuntos económicos e políticos» (McCARTHY et. al., 2009: 10).

Segundo as concepções neoliberais, o mercado deve ser o único princípio organizador de todos os serviços públicos que até há pouco tempo estavam inquestionavelmente na esfera do Estado. Este deve agora criar as condições adequadas à implementação dos mecanismos 
facilitadores do funcionamento de mercados competitivos na provisão de uma ampla variedade de serviços públicos que os cidadãos - que agora são conceptualizados como consumidores - devem escolher activamente, aceitando individualmente as consequências das suas escolhas.

A provisão de serviços públicos numa óptica neoliberal implica a reorganização e reestruturação do Estado que, longe de perder a sua capacidade de regulação e controlo (que continua a ter através de mecanismos de auditoria orientados para a medição de indicadores estandardizados), mantém algumas das suas funções reguladoras tradicionais, mas transfere para os indivíduos e para as organizações mercantis a responsabilidade histórica pela provisão desses serviços e pela garantia do bem-estar social (Klees 2002, citado em McCARTHY et. al, 2009).

Estas tendências neoliberais, ainda que de forma mais intensa e evidente nuns casos do que noutros, têm sido bem visíveis na maior parte dos países desenvolvidos e perante este novo panorama em que as instituições públicas se veem capturadas por uma concepção mercantilista de serviço público, os sistemas educativos começam a ser observados apenas e só como um meio para a «produção de capital humano suficientemente habilitado, adaptado e flexível» (McCARTHY et. al, 2009: 15).

Isto foi tendo profundos impactos naquilo que é considerado conhecimento legítimo (porque útil ao mercado) ${ }^{\mathbf{1}}$ para ser ensinado nas escolas e, consequentemente, no trabalho realizado nas instituições escolares. Trata-se de numa nova conjuntura política que Stephen Ball (2004), entre outros autores, designa de pós-Estado de Bem-Estar e que é marcada pela alteração de papéis e relações do Estado, do capital e das instituições públicas com os cidadãos, que agora são conceptualizados como os novos cidadãos-consumidores.

A consolidação desta nova conjuntura política requer, em primeiro lugar, a passagem de um Estado prestador de serviços para um Estado meramente regulador e avaliador de serviços públicos descentralizados que funcionam em regime de autonomia ou concessionados a empresas privadas, o que, em muitos sistemas, não implica

1 É esta reconceptualização da educação pública que explica, por exemplo, a diminuição do peso, ou até mesmo a retirada, das artes e das humanidades dos currículos. 
necessariamente a ausência de um Estado financiador. Consequentemente, os serviços públicos passam a ser observados pelo mercado como mais uma área de negócio e de lucros potenciais, o que cria as condições para a expansão da iniciativa privada e de parcerias público-privadas em que, muitas vezes com financiamentos públicos, se geram lucros privados. Além disso, no contexto dos processos de descentralização e autonomia, assiste-se à instalação de uma nova cultura competitiva, assente na diferenciação, no marketing, no mérito e em esquemas de recompensa e de punição em função dos resultados alcançados pelos serviços segundo padrões quantitativos de eficiência e eficácia previamente estabelecidos.

No seu incontornável livro Educación en tiempos de neoliberalismo (2001), Torres Santomé descreve de forma convincente e elucidativa como os sistemas educativos a nível mundial têm estado sujeitos a esse acentuado fenómeno de mercantilização que de dia para dia se vem consolidando através de processos de descentralização e autonomia que favorecem a excelência competitiva e a naturalização do individualismo. Pelo caminho, vão caindo no esquecimento as verdadeiras razões pelas quais se formaram os sistemas educativos públicos; vai-se perdendo gradualmente a ideia de que o principal objectivo que deveria guiar as reformas e as inovações educativas deveria ser o de garantir uma maior justiça social e uma melhor democracia.

Década após década, estes valores vão perdendo o seu vigor, num contexto em que as análises mais profundas dos problemas sociais, que procuram as verdadeiras raízes destes problemas, numa perspectiva socio-histórica, são constantemente silenciadas e desvalorizadas, ao passo que também constantemente nos querem convencer de que as soluções mercantis são as melhores de que dispomos para melhorar os sistemas educativos.

\section{Descentralização e autonomia na transição para uma era neoliberal}

Os relatórios que ao longo dos anos têm vindo a ser produzidos por diversas instituições internacionais, como é o caso do Banco Mundial (вм), da Organização para a Cooperação e Desenvolvimento Económico (OCDE) ou da União europeia (UE), entre outras, podem constituir um bom ponto de partida para perceber como têm evoluído ou como se tem esperado que evoluam os sistemas educativos públicos. 
Por uma questão de espaço, restringiremos aqui a nossa análise ao caso da União Europeia.

Por exemplo, em 2007, a Agência Europeia para a Educação, Audiovisuais e Cultura (EACEA), através da sua rede EURYDICE, que se ocupa essencialmente da produção e divulgação de informação acerca dos sistemas educativos e das políticas educativas na Europa, divulgou em 37 países europeus um importante relatório intitulado Autonomia das Escolas na Europa: Políticas e Medidas. Este documento foi solicitado pela unidade portuguesa da rede EURYDICE no âmbito da Presidência do Conselho da União Europeia e posteriormente traduzido e publicado em Portugal pelo Gabinete de Estudos e Planeamento da Educação do Ministério da Educação (GEPE-ME).

Nesse documento é reconhecido que «a autonomia das escolas está [...] a ser posta em prática em 30 países da Rede Eurydice» (EURYDICE 2007: 5), tornando-se necessária a «obtenção de um conhecimento mais completo dos processos que conduziram à transferência para as escolas dos poderes de decisão e da forma como as escolas prestam contas das suas responsabilidades perante as autoridades superiores de educação» (p. 5), uma vez que é actualmente «aceite em [...] toda a Europa o princípio de que as escolas devem ser autónomas em pelo menos algumas áreas da sua gestão [...] [Um] consenso [que] resulta de três décadas de mudanças, iniciadas paulatinamente nos anos 8o, ganhando alento nos anos 90 e nos primeiros anos deste século» (p. 6).

Segundo este influente estudo, foram os governos centrais de cada país que, influenciados por um conjunto correntes de pensamento, atribuíram novas responsabilidades às escolas, pelo que, deste modo, não foram as próprias escolas nem as comunidades locais «a força motriz do processo [de descentralização e autonomia], nem participaram na elaboração da legislação, para além da sua tradicional função de carácter consultivo» (p. 7). Além disso, é assinalado que até aos anos 80 do século $\mathrm{xx}$, «as reformas em matéria de autonomia das escolas estavam [sobretudo] relacionadas com a causa política da participação democrática e realçavam a necessidade de as escolas se abrirem mais às respectivas comunidades locais» (p. 9), uma preocupação que se manteve durante os anos 1990, mas à qual se veio juntar uma outra preocupação crescente com a «gestão eficiente dos fundos públicos» (p. 10).

É afirmado no documento que a partir dessa altura «as reformas relativas à autonomia das escolas passaram a estar fortemente 
ligadas a um movimento em duas direç̧ões: a descentralização política e a aplicação da agenda da Nova Gestão Pública [...] [que] pretende aplicar os princípios do sector privado à gestão dos serviços públicos», para com isso obter ganhos de eficiência na máquina o Estado, tendo em conta cinco aspectos fundamentais: a) «colocar o cliente no centro das atividades do Estado, alterando assim gradualmente a mentalidade do sector público; b) descentralizar as responsabilidades até ao nível mais próximo do campo de acção; c) tornar os funcionários públicos responsáveis perante a comunidade; d) aumentar a qualidade dos serviços e a eficiência dos organismos públicos; e) substituir os tradicionais procedimentos de controlo pela avaliação por resultados» ${ }^{2}$ (p. 10). Por fim, é afirmado no estudo que sob a influência daquele movimento, «na maior parte dos países, a autonomia das escolas é agora amplamente encarada como uma ferramenta a utilizar para melhorar a qualidade do ensino» (p. 10).

Segundo Torres Santomé (2001), uma das formas através da qual tem vindo a ser levada a cabo uma muito acentuada mercantilização - e consequente reconceptualização - das instituições educativas é precisamente mediante estas políticas de descentralização e autonomia dominadas por agendas como a da Nova Gestão Pública. Contudo, uma das razões pelas quais a discussão dessas políticas é bem mais complexa, controversa e frequentemente confusa do que o estudo a que acabámos de fazer referência deixa transparecer, é o facto de muitas das políticas de descentralização e autonomia terem sido originalmente grandes reivindicações dos movimentos sociais e ideológicos de Esquerda que foram posteriormente capturadas pela Direita política, desnudadas do seu significado político original e (re) significadas pelos sectores sociais mais conservadores que conseguiram atribuir-lhes todo um novo sentido, muito mais alinhado com concepções mercantilistas agora consentidas por uma opinião pública largamente manipulada por um novo senso-comum hegemónico que apenas admite a discussão das instituições e serviços públicos no quadro de vocábulos como, mérito, competitividade, eficácia e eficiência.

2 O discurso da Nova Gestão Pública conseguiu produzir e fazer circular um novo senso-comum que tem vindo a dominar a opinião pública. Basta o seguinte exemplo: de cidadãos com direitos passa-se a falar em clientes consumidores. 
As políticas de descentralização tem a sua origem «na luta, a partir de posições ideológicas progressistas, para conquistar maiores níveis de democratização e envolver, de uma maneira mais directa, a cidadania [...] [que] [...] observa nas formas mais locais de governo uma possibilidade de participar de modo mais activo e de controlar democraticamente as intervenções sociais» (TORRES SANTOMÉ 2001, p.42). Tratava-se, portanto, de estimular uma cidadania que se queria mais interventiva e comprometida com a administração local que, colaborando estreitamente com um governo representativo e democrático a quem compete criar as condições para uma educação, saúde, justiça e assistência social púbicas de qualidade, trabalharia numa perspectiva de participação democrática e de solidariedade entre os diversos grupos sociais.

No entanto, a partir de determinado momento, essas políticas de descentralização constituem também exigências dos sectores sociais mais conservadores que, acusando o Estado de despesista, ineficiente e inibidor da livre escolha, impondo a todos os cidadãos o mesmo modelo de serviços públicos, reclamam a adopção de uma gestão mais flexível desses serviços. Trata-se agora de implicar os cidadãos, enquanto consumidores, na escolha dos serviços públicos, o que, segundo esta perspectiva, implicará uma maior exigência sobre quem os fornece para garantir uma melhor qualidade, indo assim ao encontro da procura do público consumista com maior eficiência e competitividade e, portanto, segundo esta perspectiva mercantilista, com maior qualidade.

O que é notório nestas perspectivas mais recentes de índole mercantilista é uma mudança radical no centro organizador das políticas públicas que deixa de ser a construção de uma sociedade justa através da correcção dos desequilíbrios gerados pelo mercado e por uma desigual distribuição dos recursos, para passar a ser, única e exclusivamente, a relação custos-benefícios que comportam tais serviços, passando a ser o próprio mercado o centro organizador dessas políticas, supondo-se que o mesmo criará as condições para ultrapassar os efeitos perversos que ele mesmo gera.

À medida que os estados vão delegando os serviços públicos nas organizações mercantis, diminuem as despesas com gastos sociais passando a adoptar estratégias diferenciadas e complementares para o financiamento de tais serviços. Este tipo de políticas segue em linha com a suposta «necessidade» das eufemisticamente chamadas «reformas estruturais» com que as instâncias internacionais vêm 
pressionando os Estados em face do seu crescente endividamento, como tem sido agora o caso particular de muitas economias.

A coexistência destas duas linhas discursivas acerca dos processos de descentralização, uma de pendor mais progressista e outra de pendor mais neoliberal, é habitualmente usada pela Direita para produzir discursos demagógicos contra a Esquerda, acusando-a de renegar o que consistiu na verdade uma das suas reivindicações históricas. O que convenientemente não é dito é que há uma diferença substancial entre as dinâmicas de descentralização conceptualizadas a partir dos valores históricos da Esquerda e aquelas estruturadas a partir das ideologias neoliberais, que observam a sociedade como um gigantesco supermercado onde os cidadãos não passam de meros consumidores.

Visto que desde há algumas décadas a esta parte os movimentos sociais na generalidade dos países mais industrializados têm registado um significativo enfraquecimento, ao passo que a ideologia empresarial e a retórica do mercado nunca estiveram tão fortes, é evidente que todas as medidas ligadas aos processos de descentralização e autonomia se foram acabando por esculpir nesta tensão permanente entre Estado, mercado e cidadania, que, como temos visto, tem vido a ser resolvida em favor do mercado, com o consentimento de uma cidadania largamente manipulada por um novo senso-comum contra-público e pró-privado.

Ao nível internacional, a acentuação destes processos de descentralização de pendor neoliberal tem sobretudo lugar a partir da década de 80 e de 90 do passado século xx. Com efeito, é nesse período que a nível mundial se lança aquilo a que poderíamos chamar, servindo-nos aqui da expressão usada por João Paraskeva, o «rapto da instrução pública». Como salienta este autor «a base política, económica e cultural da Nova Direita não veio do nada. Uma análise verídica da sua emergência e das consequências das [suas] políticas [...] no seio da educação [...] requer examinar a emergência [...] do Reganismo e do Thatcherismo» (2004).

Baseados numa ilimitada crença no mercado livre, Regan e Thatcher iniciaram na década de 1980, nos respectivos países, uma série de profundas reformas no campo da educação - mas não só - que cedo influenciaram de forma decisiva muitos outros países e que, basicamente, se centraram na acentuação dos processos de descentralização, na emergência de um Estado avaliador em função dos resultados, no incentivo da iniciativa privada, na instituição de uma nova cultura 
competitiva e na reconceptualização da educação pública como um serviço público de educação e dos cidadãos como consumidores.

\section{Descentralização e autonomia escolar... em Portugal: Um modelo a evitar}

Em Portugal, as primeiras referências explícitas à autonomia das escolas, que marcam o início de uma referência continuada à autonomia escolar nas políticas educativas, surgem enquadradas pela Reforma Educativa que dominou a segunda metade dos anos 80 do século xx. A 1 de Janeiro de 1986, Portugal assina o tratado de adesão à então denominada Comunidade Económica Europeia (CEE). Volvidos quase doze anos sobre a revolução de 25 de Abril de 1974, Portugal era um país atrasado, tanto no contexto nacional como no plano europeu. A adesão à cEE foi vista como um passo imprescindível para o desenvolvimento do país, um apoio decisivo para a superação dos atrasos em muitos sectores, como era o caso da educação.

Alguns dias antes, em Dezembro de 1985, por resolução do Conselho de Ministros, tinha sido criada a Comissão de Reforma do Sistema Educativo, que logo no seu Projecto Global de Atividades salientava a inadequação dos esquemas de gestão do ensino e propunha a implementação de políticas de descentralização que consagrassem «uma ampla autonomia das escolas, dos pontos de vista administrativo e financeiro e da organização e funcionamento pedagógico» (CRSE 1986: 49).

É assim que surge o Decreto-Lei n. ${ }^{\circ}$ 83/89, de 3 de Fevereiro, no qual se afirma que «entre os factores de mudança da administração educativa inclui-se, como factor preponderante, o reforço da autonomia da escola», de onde resulta a transferência de alguns "poderes de decisão para os planos regional e local», destacando-se sobretudo a flexibilização da gestão financeira das escolas, para além da obrigatoriedade de elaboração de um projecto educativo próprio de cada estabelecimento de ensino.

Mais tarde é o Decreto-Lei n. ${ }^{\circ} 115-\mathrm{A} / 98$, de 4 de Maio, que, no quadro de um governo socialista, aprofunda os princípios da autonomia das escolas. Neste Decreto-Lei de 1998 é explicitado que a «autonomia das escolas e a descentralização constituem aspectos fundamentais de uma nova organização da educação, com o objectivo de concretizar na vida da escola a democratização, a igualdade de 
oportunidades e a qualidade do serviço público de educação». Refere-se que a «autonomia não constitui, pois, um fim em si mesmo, mas uma forma de as escolas desempenharem melhor o serviço público de educação, cabendo à administração educativa uma intervenção de apoio e regulação [...]» pelo que se prevê «a figura inovadora dos contratos de autonomia». Desde esta altura, acentuou-se a delegação de poderes e funções nas instituições locais e nas próprias escolas, com o argumento de que as estas saberiam adaptar melhor os recursos disponíveis e tomar decisões mais informadas, visto estarem mais próximas das populações.

Mas a concretização deste argumento suporia naturalmente a criação de condições para o desenvolvimento de uma intensa e verdadeira cultura de participação por parte de todos os grupos sociais e instituições locais interessados pela educação escolar enquanto projecto político estratégico para o planeamento de um futuro que se pretendia democrático e assente numa cidadania participativa, crítica e solidária. Seria da participação e da discussão intensas que nasceriam os critérios de qualidade de uma educação pública comprometida com os valores da cidadania democrática e com a educação integral das crianças e jovens no respeito por tais valores.

Contudo, não foi bem isto que aconteceu. O que fomos verificado é que tais critérios de qualidade acabaram definidos praticamente sem nenhuma participação e, o que é mais grave, influenciados por um ambiente social muito receptivo à ideologia de mercado, sendo por isso reduzidos a meras metas quantitativas ligadas ao cumprimento de um currículo uniforme do género "pronto-a-vestir», para nos servirmos aqui a metáfora de João Formosinho (2007), e do qual foram desaparecendo áreas essenciais (artes e humanidades) para a formação integral das crianças e dos jovens, mas pouco queridas aos mercados. As questões curriculares, que são o núcleo organizador do trabalho escolar, estruturantes das relações entre a classe docente $\mathrm{e}$ a população estudantil e as suas famílias, foram permanecendo intocadas e foram sempre geridas centralmente, sem qualquer tipo de contextualização e incorporação de saberes e práticas locais.

Mesmo ao nível financeiro e administrativo, uma melhor adaptação aos contextos locais suporia a necessária afectação dos recursos materiais e humanos para fazer face às características específicas de cada comunidade ou território. Pelo contrário, o que foi sucedendo foi uma constante crítica à despesa pública com a educação, reivindicando-se progressivamente a gestão das escolas segundo os critérios da 
competitividade dos mercados e a sua avaliação periódica com base em standards publicados periodicamente em rankings escolares.

Hoje, volvidas algumas décadas, é possível encontrar toda uma retórica e um conjunto de práticas que deixam perceber claramente a consolidação de uma concepção managerialista da educação no sistema educativo português altamente comprometida com uma visão mercantil da educação. Tanto o Decreto-Lei n. ${ }^{0}$ 75/2008, de 22 de abril, como os decretos-lei que se lhe seguiram (Decreto-Lei n. ${ }^{\circ}$ 224/2009, de 11 de Setembro; Decreto-Lei n. ${ }^{0}$ 137/2012, de 2 de Julho) - que definem o regime jurídico da autonomia das escolas - se encaminham nesta linha.

\section{Para não concluir...}

Este não é um texto contra o mercado e muito menos contra a iniciativa privada. De resto, como é bem claro na Lei de Bases do Sistema Educativo, em Angola «as iniciativas de educação podem pertencer ao poder central e local do Estado ou a outras pessoas singulares ou colectivas, públicas ou privadas» (p. 3). E de facto, as escolas privadas podem ter um papel de grande relevância social ao oferecer às famílias projectos educativos diferentes dos da escola pública, mais congruentes com o ideário educativo dessas famílias.

O que é preciso ter presente é que a educação é acima de tudo um projecto político, uma vez que se centra no desenvolvimento, pelas gerações mais jovens, de um conjunto de conhecimentos, capacidades, valores e atitudes que são considerados essenciais para a preparação de um futuro que se pretende democrático e socialmente justo.

Desta forma, são os valores da democracia e da justiça social que devem guiar as reformas e as inovações educativas. Mas o que tem vindo a acontecer na maior parte dos países industrializados do mundo é um cada vez mais acentuado recuo destes valores, à medida que avança a retórica individualista e competitiva de mercado.

Revela-se assim premente a necessidade de adoptar uma postura crítica face aos modelos internacionais de gestão e administração educativa que são adoptados para análise como casos de estudo. Por exemplo, muito embora haja aspectos a olhar com interesse nas políticas de descentralização e autonomia que foram sendo desenhadas em Portugal, elas devem ser questionadas dada a sua natureza híbrida que resulta de um emaranhado influências 
ligadas a correntes de pensamento diversificadas. Por trás delas está um novelo ideológico é preciso desatar.

Portanto, na hora de decidir que caminho tomar em matéria de descentralização e autonomia educativa é crucial saber para onde ser quer ir, ou seja, que tipo de políticas de descentralização e autonomia se quer desenhar: fundadas nos valores progressistas históricos ou na retórica alienante do mercado?

\section{Referências bibliográficas}

\section{BALL S.}

2004, «Performatividade, privatização e o pós-Estado do Bem Estar», Educação \& Sociedade, vol. 25, n. ${ }^{\circ}$ 89, pp.1105-1126.

BAUMAN Z.

2011, «Prefácio», in D. Macedo. A democracia imposta. Diálogos com Noam Chomsky e Paulo Freire. Mangualde, Edições Pedago, pp. 7-12.

CASTELls M.

2007 ( $3 \cdot^{\text {a }}$ edição), A era da informação: Economia, Sociedade e Cultura. Volume 1, A Sociedade em Rede. Lisboa, Fundação Calouste Gulbenkian.

CRSE

1986, Projecto global de actividades. Lisboa, Ministério da Educação.

\section{EURYDICE}

2007, Autonomia das escolas na Europa. Políticas e medidas. Lisboa, GEPE - Ministério da Educação. Disponível em linha em $<$ http://eurydice.gepe.min-edu.pt>

FormosinHo J.

2007, O currículo uniforme ponto-a-vestir de tamanho único. Mangualde, Edições Pedago.

GewirTz S.

2002, The managerial school. Londres, Routledge.

KuMASHIRO K. K.

2008, The seduction of common sense. How the right has framed the debate on America's Schools. New York: Teachers College Press.

McCARTHY C. et. al.

2009, Movimento e inércia na reorientação neoliberal da Educação. Mangualde, Edições Pedago. 


\section{PARASKEVA J. M.}

2004, «O nome, a coisa e... o currículo. Perversos motes da perigosa glosa neo-centralista radical», Educação \& Psicologia, vol. 16 , n. ${ }^{\circ}$, pp. $101-113$.

Patacho P.

2013, «Mercantilização da educação: Tendências internacionais e políticas educativas em Portugal», Currículo sem Fronteiras, vol. 13, n. $^{\circ} 3$, pp. 561-587.

\section{SANTOMÉ J. Torres}

1998 (5. ${ }^{\text {a }}$ reimpressão), El curriculum oculto. Madrid, Ediciones Morata.

2000 ( $4 .^{\mathrm{a}}$ reimpressão). Globalización e interdisciplinariedad: El curriculum integrado. Madrid, Ediciones Morata. 2001, Educación en tempos de neoliberalismo. Madrid, Ediciones Morata.

\section{SANTOS B. S.}

2006, A gramática do tempo: Para uma nova cultura política. Porto, Afrontamento.

\section{Torres Santomé J., ver SantomÉ J. Torres, supra}

VIÑAO A.

2007, Sistemas educativos, culturas escolares e reformas. Mangualde, Edições Pedago.

Recepção do manuscrito: 03/02/2016

Aceite para publicação: 20/06/2016

Title: International trends in the management and administration of education: policies of decentralization and autonomy

\footnotetext{
Abstract: School autonomy as a management and public administration policy results from a gradual process of transferring power to educational institutions, accompanied by the definition of accountability mechanisms. At the outset, school autonomy reforms were mainly related to the political cause of democratic participation and to the idea of social justice, stressing the need for schools to open to their local communities. This concern has been losing momentum in recent decades, as another has overtaken it, especially influenced by the agenda of the new public management that, served by a neoliberal ideology, intends to apply the principles of the private sector to the management of public services. In the case of the education sector, the most visible effect has been a commodification - and consequent reconceptualization - of the public school through these managerial policies of decentralization and autonomy. Along the way, the real reasons behind the formation of public education systems have been forgotten. The idea that the main goal that should guide education reforms and innovations should be to ensure greater social justice and a better democracy is losing terrain.
} 
Keywords: School autonomy, decentralization, public policies, school management and administration.

\section{Pedro Patacho}

Licenciado em Ensino na variante Matemática e Ciências da Natureza pelo Instituto Superior de Ciências Educativas (2000), onde é professor desde 2009, Mestre em Educação pela Universidade de Lisboa e Doutor em Didáctica e Organização Escolar pela Universidade da Coruña (Reino de Espanha). É investigador do Centro de Investigação do Instituto Superior de Ciências Educativas (CI-ISCE) e do Centro de Recursos Pedagógicos da Faculdade de Ciências Sociais da Universidade Agostinho Neto (CEREPE). Professor convidado da FCS-UAN desde 2013, as suas áreas de interesse situam-se no âmbito da análise sociopolítica da educação e dos sistemas educativos, com uma particular ênfase na análise dos processos democráticos no seio das organizações educativas. Director das Edições Pedago, que ajudou a fundar em 2004, aí fez publicar vasta obra de uma ampla diversidade de autores críticos no campo das ciências sociais e, mais recentemente, em parceria com as Edições Mulemba da FCS-UAN, diversas obras de autores africanos e africanistas, bem como várias revistas científicas. Foi membro da Comissão Organizadora da I Trienal das Humanidades: As humanidades e o desenvolvimento de Angola num mundo multicultural e globalizado, promovida pela Universidade Agostinho Neto em 2014. É membro do Conselho Científico da Mulemba - Revista Angolana de Ciências Sociais, e do Conselho Editorial da RAS - Revista Angolana de Sociologia, é também membro do Editorial Advisory Board do Journal of Critical Education Policy Studies. Entre os seus trabalhos mais recentes contam-se: «Escolas, culturas escolares e a formação de professores para trabalhar com as famílias», in L. R. Oliveira et al. (org.), Actas do colóquio Desafios curriculares e pedagógicos na formação de professores. Braga, Universidade do Minho, 2015, pp. 80-87; «Cheik Anta Diop e o desafio para as novas gerações africanas: Notas a propósito de uma obra de Jean-Marc Ela», Mulemba - Revista Angolana de Ciências Sociais (Luanda), vol. Iv, n. ${ }^{\circ}$ 8, Novembro de 2014, pp. 585-591; «Concepções e práticas pedagógicas no ensino das Ciências Sociais e Humanas», Mulemba - Revista Angolana de Ciências Sociais (Luanda), vol. Iv, n. ${ }^{\circ}$, Maio de 2014, pp. 291-308, em co-autoria com Cesaltina Abreu e Eugénio da Silva; «Revoluções, crises e a emergência de um Novo Mundo", Mulemba - Revista Angolana de Ciências Sociais (Luanda), vol. Iv, Maio de n. ${ }^{\circ}$ 7, 2014, pp. 355-370; «Mercantilização da educação: Tendências internacionais e as políticas educativas em Portugal, Currículo sem Fronteiras, vol. 13, n. ${ }^{\circ}$ 3, 2013, pp. 561-587; "Paradigmas de investigação em Ciências Sociais», Mulemba - Revista Angolana de Ciências Sociais (Luanda), vol. III, n. ${ }^{\circ}$ 6, Novembro de 2013, pp. 13-28; "Quando a subjectividade se torna conhecimento 
científico. Ferrarotti e a abordagem biográfica nas ciências sociais», Mulemba - Revista Angolana de Ciências Sociais (Luanda), vol. III, n. ${ }^{\circ}$ 6, 2013, pp. 361-366.

[e-mail: ppatacho@yahoo.com] 